\title{
Are Leaders' Personality Traits Imperative For Employees' Job Performance? The Context Of An Emerging Economy
}

\author{
Bilal Anwar, Xi'an Jiaotong University, China \\ Zhongdong Xiao, Xi'an Jiaotong University, China \\ Muhammad Fiaz, Xi'an Jiaotong University, China \\ Amir Ikram, Xi'an Jiaotong University, China \\ Muhammad Younas, University of Engineering \& Technology, Pakistan
}

\begin{abstract}
Leader's personality considerably influences the behavior of employees and is perhaps one of the most important predictor of their job performance. The purpose of the study was to evaluate the personality-performance paradigm in the context of emerging economies. Personality was assessed through big five traits, namely openness to experience, conscientiousness, extraversion, agreeableness and neuroticism. While task performance attribute of job performance was considered as dependent variable. Stratified sampling technique was deployed to gather data from 149 SMEs belonging to diversified business sectors operating in the industrial city of Gujranwala, Pakistan. Cronbach's alpha test endorsed the consistency of survey questionnaire, and multiple regression analysis was used to test hypotheses. All of the personality traits, with the exception of neuroticism, are found to be valid predictors of employee job performance, though the degree and significance of correlation varies. The study contributes to the enhanced understanding of the personality-performance relationship and highlights the desirable personality inventories of potential leaders and entrepreneurs. Broader practical implications and recommendations for future research bring the discussion to the close.
\end{abstract}

Keywords: Big Five Traits; Employee Job Performance; Leaders; Personality; Pakistan; SMEs

\section{INTRODUCTION}

lobalization and ever changing dynamics of the global competition are driving organizations to have the versatile manager and leaders, who can comprehend diversified employees and enhance organizational performance. Leaders of today hail from different backgrounds and entail diversified attitudes, norms and values. The scenario calls for analyzing leader-follower interactions and highlight the vital dimensions of personalityperformance paradigm. Personality traits are related to effectiveness of the enterprise, as leadership is a function of personality (Hogan and Bensen, 2009). Thus, personality traits of managers and leaders determine the decisional aspects and decide whether decision-making is centralized or not (Byrne, Silasi-Mansat \& Worthy, 2015). Literature of psychology and organization behavior suggest that leader's personality and effectiveness can be best explained through evaluating Big Five personality traits, namely openness to experience, conscientiousness, extraversion, agreeableness and neuroticism (Norman, 1963), sometimes referred to by the acronym OCEAN for mnemonic simplicity (Barrick \& Mount, 1991; Leutner, Ahmetoglu, Akhtar \& Chamorro-Premuzic, 2014). Whereas, job performance refers to employee participation in realizing organizational objectives (Awadh and Ismail, 2012); it ensures effective functioning of the organization as a whole, and is perhaps one of the key dependent variables that has been scrutinized for decades. Bhatti, Battour, Ismail and Sundram (2014) explained job performance as a multidimensional construct, comprising task dimension and contextual dimension. Recent studies exhibit that leaders' personality traits influence the job performance of the subordinates at large (Blickle et al., 2015; Leutner et al., 2014). 
Since the arrival of $21^{\text {st }}$ century, Pakistan has been going through a roller coaster period, marked by low technical efficiency of the enterprises (Ikram, Su \& Sadiq, 2016). The resultant changes at the enterprise level are enormous as managers and subordinates endeavor to endure in a performance-based competitive environment. In such dynamic environment, transformational managers and leaders are persuaded to deliver in an effective and vigorous manners and demonstrate the true colors of their personality. Hence it is of paramount importance to have a broader understanding of personality-performance paradigm in the context of Pakistan in order to derive a framework to recruit and develop leaders of tomorrow in emerging and turbulent economies. Potential leaders and entrepreneurs need to comprehend the multifarious process in which personality attributes shape activities and influence organizational outcomes. But there is hardly any study that explores this interesting relationship with the cultural aspects of Pakistan. We fill the literature gab by investigating the relationship between leader's Big Five personality traits and employee job performance by investigating 149 SMEs in the Gujranwala city of Pakistan. Gujranwala is an industrial city in the north of Punjab province, encompassing more than 6,500 SMEs and 25,000 cottage units (Gujranwala Business Centre, 2016). Being an industrialized hub, the investigation of the prevalent leadership traits would give prolific pragmatic implications. In this paper, we seek to resolve the following research questions: (a) How significant are the personality traits for enhancing job performance? (b) Which personality traits to look for while establishing desirable personality inventories? (c) How entrepreneurs and leaders of emerging economies cope with complexities of highly dynamic environment? Rest of the paper is arranged in the following sequence: Theoretical background of the leadership traits from the perspective of Big Five model and its impact on employees' job performance, and hypotheses formulation are discussed in section 2. In section 3, we elaborate research approach and sample characteristics. Analysis of data and results is deliberated in Section 4. Conclusion and practical implications for leaders and entrepreneurs bring the discussion to a close.

\section{THEORETICAL BACKGROUND AND HYPOTHESES FORMULATION}

\subsection{Leaders' Personality Traits from the Spectrum of Big Five Model}

Barrick and Mount (1991) refers to personality as set of indiscernible features and practices that exist behind a relatively steady array of activities in response to the various entities prevalent in the environment. It is an effective predictor of employee job performance, as broadly validated by criterion-related investigation of Chamorro-Premuzic and Furnham (2010). Historically speaking, leadership researchers were curious to know, do leaders arise due to their personality? Though there are many approaches to leadership, for instance, instrumental approach and symbolic approach (Andersen, 2000), the personality approach to leadership and the association between personality and leadership is perhaps widely talked about (Haynes, Hitt \& Campbell, 2015). Hogan and Bensen (2009) endorsed the empirical links among personality, leadership and organizational effectiveness through leadership value chain. Moreover, the personality-performance linkage is prevalent across all decision-making and hierarchy levels (Barrick \& Mount, 1991; Barrick, Stewart, \& Piotrowski, 2002).. Negative side of personality, such as aggressiveness and narcissism, can be detrimental for the organization and can result in destructive work attitudes (Klotz \& Neubaum, 2016; Miller, 2014; Palaiou, Zarola \& Furnham, 2016)). For instance, greed on the part of leaders and entrepreneurs diminishes employee's performance and organization's productivity (Haynes et al., 2015). However, DeNisi (2015) suggests that possession of negative personality aspects does not necessarily result in deeds of malpractices. In the domain of psychology, there is a widespread consensus to gauge personality traits through the spectrum of 'Big five model' (Alkahtani, Abu-Jarad, Sulaiman \& Nikbin , 2011; Barrick, Stewart, \& Piotrowski, 2002; DiNisi, 2015). The predictive power of the personality model is vigorous across various domains, be it individual, interpersonal, or institutional. During the past three decades, vast amount of literature provides convincing substantiation for the robustness of the five factor model. Tupes and Christal (1961) are the first to have labelled personality traits into five broad categories, namely surgency, agreeableness, dependability, culture and emotional stability. However, it was Norman's labelling of personality traits in 1963 which form the basis of 'Big Five factors.'

The Big five personality model is sometimes represented by the acronym of OCEAN; openness, consciousness, extraversion, agreeableness and neuroticism (Barrick \& Mount, 1991). Mark and John (2000) explored the relationship of openness to experience and job performance, and reveals that this particular trait predicts distinctive variance in job performance for personnel; they further suggest that leaders who are more open to experience can cope and resolve the conflicts positively and thereby enhances job performance. Conscientiousness is the trait of competence, 
dutifulness, achievement orientation and self-discipline (Leutner et al., 2014); this trait is found to be the most descriptive of employee job performance (Hurtz \& Donovan, 2000). Extraversion is perhaps the most important traits of leadership and is the extent to which individuals are emphatic, invigorated and eager (Solaja, Idowu \& James, 2016). Extraverted leader tends to be more efficacious because they are more likely to be conversational, sociable and network-oriented (Colquitt, Le-Pine \& Wesson, 2009). An empirical study in the context of Germany shows that asymptotic relationship between of extraversion and enterprising job performance (Blickle, Meurs, Wihler, Ewen, Merkl, \& Missfeld, 2015)). Encouraged and enthused by the desire to mingle with members, extraverted leader is supposed to enjoy a spirited existence and seek eagerness and inspiration (Alkahtani et al., 2011). Thus, the subordinates are likely to recognize their leader as jovial and optimistic. Agreeableness is a tendency to be selfsacrificing, supportive, accommodating, gentle and kind. Such leaders concern for their subordinates at workplace and they are likely to be fretful of employee's growth trajectory (Judge \& Zapata, 2015). Last of all, Neuroticism is a propensity of fear, sorrow, shame, guilt, depression and disgust. Since it is necessarily a negative attribute, leaders with neuroticism display consistently negatively correlation with leadership emergence and effectiveness. So the leader with high neuroticism usually fails to foresee task-based criteria, for example quality and quantity of job performance among the personnel (Niehoff, 2006). Leaders exhibiting neuroticism characteristic tend to be less effective than their fervently stable counterparts (Barrick \& Mount, 1991). Neuroticism was found to be associated with impaired decision-making under pressure (Byrne, Silasi-Mansat \& Worthy, 2015). Jeronimus, Kotov, Riese \& Ormel (2016) advocated that high level of neuroticism antedates the growth of almost all common mental ailments. There is a debate whether personality can be nurtured or not. Lounsbury, Smith, Levy, Leong \& Gibson (2009) conducted empirical study of 347 undergraduate business majors and 2252 nonbusiness majors, and suggested managers with business majors ranked superior for conscientiousness, extraversion, emotional strength, and decisiveness, however they recorded lower scores for agreeableness and openness. Judge and Bono (2000) linked leadership with the Big Five model of personality and suggested the potential deployment of Big-Five personality traits to recruit and evaluate transformational leaders.

\subsection{Job Performance}

Job performance refers to the behaviors that can be regulated by the individuals themselves and contribute towards attainment of organizational goals (Rotundo \& Sackett, 2002). Jex (1998) broadly defined it as 'all kinds of behaviors at work' and regarded it as the most important research criterion of organizational behavior. They can be distinguished based on their effectiveness, which has a potential influence on results (Borman \& Motowidlo, 1997). As per Gerhart, B., \& Fang, M. (2014), job performance can be narrowly defined as employee productivity, while comprehensively speaking; it is the combination of skills and outcomes gained. Performance measures include precision, quantity of work done, and highest level of accomplishment (Touré-Tillery \& Fishbach, 2014). Researchers broadly classify employee performance into two broad categories; task performance and contextual performance or citizenship behavior (Bhatti et al., 2014; Borman \& Motowidlo, 1997). Jalalkamali, Ali, Hyun, \& Nikbin (2016) reveals that communication satisfaction significantly influences both dimensions of job performance. Task performance encompasses activities that uphold an enterprise's technical aspects and operationalization of technical processes. It is considered as one the most important dimention of work ethics, and at times substituted for the notion of 'overall job performance'. Contextual performance entails activities that are over and above organizational task requirements and depicts employee's citizenship behavior (Bhatti et al. 2014; Borman \& Motowidlo, 1997). While distinguishing contextual and task actions, Borman and Motowidlo (1997) presented a taxonomy of contextual performance comprising elements of social-oriented organizational behavior and organizational citizenship behavior. Literature has widely endorsed the relationship between leadership's personae and employee job performance (Barrick, Stewart, \& Piotrowski, 2002; Rothmann \& Coetzer, 2003; Solaja et al., 2016). Judge and Zapata (2015) evaluated the degree of association between five-factor personality model and job performance, and suggests that all five factor of big five model are valid predictors of employee performance. Yeh et al. (2016) gave an interesting aspect to this relationship, by analyzing the moderating role of leadership on the association between personality traits and job performance. 


\subsection{Hypotheses Formulation}

On the basis of aforementioned theoretical background, the following hypotheses are formulated to examine the significance and relationship for each element of the big five personality traits with employee job performance:

H1: The relationship between openness to experience and employee job performance is a significant.

H2: Conscientiousness on the part of leaders significantly influences job performance of employees.

H3: Leader's extrovert behavior significantly impact employee job performance.

H4: There is a significant association between leader's agreeable attitude and employee job performance.

H5: Leader's neurotic personae significantly affects employee job performance.

\section{RESEARCH APPROACH}

\subsection{Theoretical Framework}

Figure 1 elaborates the theoretical framework and depicts hypotheses formulation, wherein each of the elements of big five model are considered as independent variables, and employee job performance is labeled as dependent variable.

Figure 1. Theoretical framework of personality traits and employee job performance

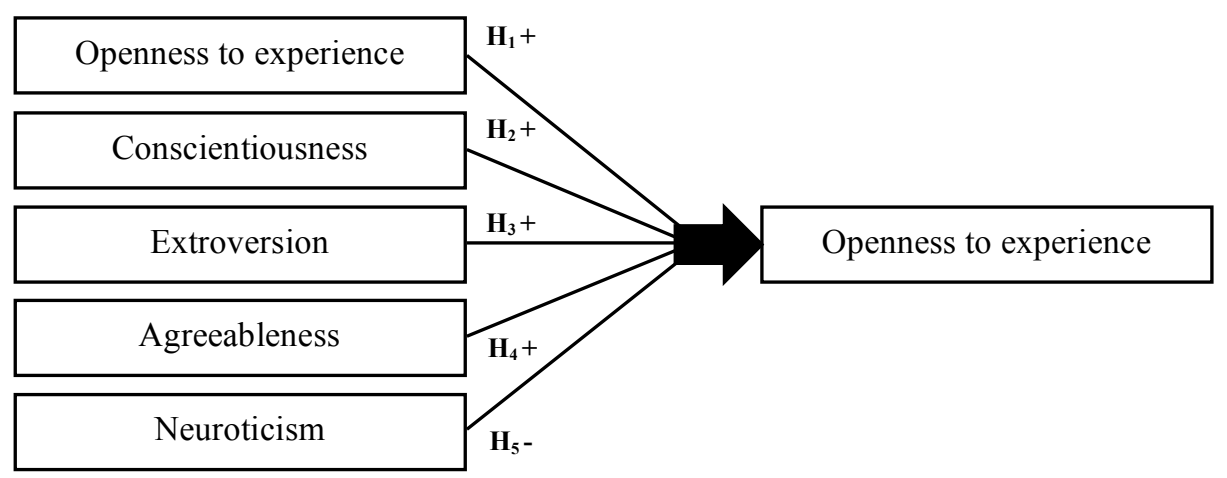

Independent Variables

Dependent Variable

\subsection{Regression Model}

Since multiple regression is considered as a flexible data analytic tool for investigating data pertaining to behavioural sciences (Cohen, Cohen, West, \& Aiken, 2013), it was used to explore the combined effect of the variables of five personality traits on employees' task performance:

TasPer ts $=\beta_{0}+\beta_{1}\left(\mathrm{Opn}_{\mathrm{npi}}\right)+\beta_{2}\left(\mathrm{Con}_{\mathrm{npi}}\right)+\beta_{3}\left(\mathrm{Ext}_{\mathrm{npi}}\right)+\beta_{4}\left(\mathrm{Agr}_{\mathrm{npi}}\right)+\beta_{5}\left(\mathrm{Neu}_{\mathrm{npi}}\right)+\eta \mathrm{i}+\varepsilon \mathrm{it}$ 
The operationalization of dependent and independent variables are as follows:

- $\quad$ TasPer $_{\text {ts }}=$ Task Performance (time spent)

- $\quad \mathrm{Opn}_{\mathrm{npi}}=$ Openness to experience (Neo Personality Inventory)

- $\quad$ Con $_{n i}=$ Consciousness (Neo Personality Inventory)

- $\quad$ Ext $_{\text {npi }}=$ Extroversion (Neo Personality Inventory)

- $\quad \mathrm{Agr}_{\mathrm{npi}}=$ Agreeableness (Neo Personality Inventory)

- $\quad \mathrm{Neu}_{n \mathrm{ni}}=$ Neuroticism (Neo Personality Inventory)

- $\eta \mathrm{i}=$ unobservable heterogeneity

- $\varepsilon=$ error term

- $\mathrm{B} 0=$ constant variable

- $\mathrm{B}_{1}, \beta_{2}, \beta_{3,}, \beta_{4} \& \beta_{5}=$ Proportional change in the dependent variable caused by independent variables.

For the purpose of evaluating task dimension of job performance, various criteria can be deployed such as cycle time, cost, production rate and error rate. Veldhoven (2014) elaborated measures of task performance and proposed contextdependent and flexible framework with quantitative measures. They suggested that 'time spent' dimension is an important approach in measuring task performance. Over here, the assumption that the time spent on the task completion is an indication of quality, but this 'the-faster-the-better' approach has the tendency to affect quality and safety aspects. Task performance was measured through 'time spent' dimension, while the personality variables of big five model were operationized by the 240-item NEO PI-R Personality Inventory Form S, which is a self-reporting form (Costa \& McCrae, 1992). Each domain element has further six aspects and each aspect is evaluated with eight items. A 5-point scale was deployed ranging from 1 (strongly disagree) to 5 (strongly agree).

\subsection{Data Collection}

The cross-sectional study was conducted to examine the personality-performance paradigm prevalent in an emerging industrial city. The members' directory of Gujranwala Chamber of Commerce and Industry provided list of SMEs operating in the city and belonging to diversified sectors ${ }^{1}$. Stratified random sampling technique was deployed to collect data through comprehensive survey questionnaire from 149 SMEs operating in the city of Gujranwala, Pakistan. Selection of stratified sampling technique relates with the SME definition of Pakistan, whereby no distinction is made between small and medium enterprises ${ }^{2}$. The sampling technique ensured proportionate representation of both small and medium enterprises. As per the available data, there are 663 small \& medium enterprises in the city of Gujranwala, having workforce of 100 or less than 100; and 218 enterprises have workforce in the range of 101-250. In total, 161 SMEs were contacted, and 12 enterprises did not respond; so we were left with final sample size of 149 SMEs. Research design of the study is multiple regression model, in view of it appositeness to tests statistical association between variables. Multiple regression is regarded as a flexible data analytic tool, and therefore serves as a broad system for investigating data in behavioural sciences (Cohen et al., 2013).

Table 1. Sample Characteristics

\begin{tabular}{l|c|c|c}
\hline \multirow{3}{*}{ Gender } & Attributes & Frequency & \multicolumn{2}{c}{ Percentage } \\
\hline \multirow{3}{*}{ Age } & Males & 94 & $63 \%$ \\
\cline { 2 - 4 } & Females & 55 & $37 \%$ \\
\hline \multirow{2}{*}{} & $20-29$ & 32 & $21.3 \%$ \\
\cline { 2 - 4 } & $30-39$ & 97 & $65.3 \%$ \\
\cline { 2 - 4 } & $40-49$ & 14 & $9.3 \%$ \\
\cline { 2 - 4 } & Above 50 & 6 & $4 \%$ \\
\hline
\end{tabular}

\footnotetext{
${ }^{1}$ Gujranwala Chamber of Commerce \& Industry provides members' directory belonging to 32 sectors, ranging from agriculture to industry, plastic to steel, etc. <http://www.gcci.org.pk/pgMemberdirectory.aspx>

${ }^{2}$ In Pakistan, SME definition differentiate small and medium enterprises; businesses having 100 or less employees are categorized as small enterprise, while organizations having employees from 101-250 are regarded as medium enterprise <www.smeda.gov.pk> Copyright by author(s); $\underline{\mathrm{CC}-\mathrm{BY}}$ 
Table 1 shows the sample attributes with respect to gender and age; out of 149 respondents, $94(62.7 \%)$ were male whereby $56(37.3 \%)$ were female. Considering the male-oriented business society, the high concentration of males is understandable. With respect to age, it was stated that 98 (65.3\%) respondents' age falls in the age bracket of 30 to 39 years old, $32(21.3 \%)$ respondents range from age bracket 20 to 29 years, $14(9.3 \%)$ respondents' age range from 40 to 49 years, and $6(4 \%)$ respondents' aged 50 years and above.

\subsection{Research Instrument and Scale Reliability}

Being an industrial city, Gujranwala encompasses wide range of entrepreneurs belonging to industrial machinery, motor pumps, washing machines, fan industry, electrical products, poultry forage, soap, kitchen accessories, sanitary, and numerous agricultural products etc. This results in a sample with high level of diversity and, thereby, increased variance and external validity. Respondents were asked to identify and rank their degree of personality traits, using a 5-point Likert scale (stretching from strongly agree to strongly disagree).

Table 2. Reliability test for independent variables

\begin{tabular}{l|c}
\hline \multicolumn{1}{c}{ Sample attributes } & Cronbach's $\boldsymbol{\alpha}$ \\
\hline Openness to experience & 0.897 \\
\hline Conscientiousness & 0.854 \\
\hline Extraversion & 0.908 \\
\hline Agreeableness & 0.888 \\
\hline Neuroticism & 0.873 \\
\hline
\end{tabular}

The reliability test of Cronbach's alpha depicts high internal constancy and validity with coefficient values ranging from 0.854 to 0.908 for each of the five personality variables (see Table 2). If alpha value is in the range of 0.80 to 0.90 (i.e. $0.9>\alpha \geq 0.8$ ), it depicts good internal consistency (DeVellis, 2012). The highest alpha coefficient 0.908 for the trait of extraversion, after that openness to experience variable with value of 0.897 , agreeableness with value 0.888 , neuroticism 0.873 , and finally conscientiousness with the numeral of 0.854 .

\section{RESULTS AND ANALYSIS}

Multiple regression model was used to inspect the link between employee job performance and five personality traits; i.e. the independent variables of openness, conscientiousness, extroversion, agreeable attitude and neuroticism. The model in respect of task performance incorporates five independent variables, and the categorical variable is significant $(\mathrm{p}=0.00)$ as depicted in Table 3 . The adjusted $\mathrm{R}$ square is 28.0 percent, which depicts that $28 \%$ of the variation in task performance investigated in this study can be explained by the five variables specified in the model. The variables of openness to experience, consciousness, extraversion and agreeableness are positively associated; consciousness is statistically significant at 1 percent level, extroversion and agreeableness is statistically significant at 5 percent level, while openness to experience is insignificant at all conventional levels of significance. The outcomes are consistent with the findings of Hogan and Holland (2003); they advocated that agreeableness, extraversion and openness to experience are significant predictors of team performance. Hurtz and Donovan (2000) suggested that personality attribute of conscientiousness is the most significant predictive of employee job performance. However, one discrepancy is there, i.e. insignificance of the openness to experience. This can be attributed to the lack of innovativeness and creativity on the part of enterprises under study. 
Table 3. Standard multiple regression results for task performance

\begin{tabular}{|c|c|c|c|c|}
\hline Variables & Beta & t-value & Significance & VIF \\
\hline Constant & & 3.298 & 0.005 & \\
\hline Opn & 0.499 & 0.896 & 0.213 & 2.05 \\
\hline Con & 0.546 & 2.218 & $0.008 *$ & 1.98 \\
\hline Ext & 0.504 & 3.257 & $0.042 * *$ & 1.02 \\
\hline Agr & 0.594 & 2.661 & $0.036^{* *}$ & 3.26 \\
\hline $\mathrm{Neu}$ & -0.113 & -1.062 & 0.181 & 2.97 \\
\hline Adjusted $\mathrm{R}^{2}$ & \multicolumn{4}{|c|}{27.0} \\
\hline F-statistic & \multicolumn{4}{|c|}{5.012} \\
\hline Significance & \multicolumn{4}{|c|}{0.0000} \\
\hline
\end{tabular}

** Coefficients are shown as significant at $5 \%$ or * $1 \%$ level

The results appear to suggest that in the context of Pakistan, task performance are more closely related to consciousness and agreeableness rather than openness. Consistent with expectation, neuroticism and employee job performance exhibits negative relationship, though the relationship is not significant at conventional levels. Prior studies advocated that high degree of neuroticism is associated with unfitting decision-making and leadership infectiveness, which in turn leads to lessened employee job performance (Byrne, Silasi-Mansat \& Worthy, 2015; Judge et al., 2002; Niehoff, 2006). The non-significance of the neuroticism variable suggests that it does not have much of a prevalence among the enterprises under investigation. Moreover, multicollinearity was gauged using the variance inflation factor (VIF) computed by the regression analysis. If VIF exceeds 10, multicollinearity is perceived as a problem (Gujarati, 1995). Table 3 depicts that the largest VIF is 3.260. Thus it is fair enough to say that multicollinearity is not an issue in inferring the regression results.

Table 4. Hypotheses Testing

\begin{tabular}{l|c}
\hline \multicolumn{1}{c}{ Hypotheses } & Strength and nature of association \\
\hline $\mathrm{H}_{1}:$ Openness to experience and employee & Insignificantly positive \\
\hline $\mathrm{H}_{2}:$ Conscientiousness and employee job & Significantly positive \\
\hline $\mathrm{H}_{3}:$ Extroversion and employee job performance & Significantly positive \\
\hline $\mathrm{H}_{4}:$ Agreeableness and employee job performance & Significantly positive \\
\hline $\mathrm{H}_{5}:$ Neuroticism and employee job performance & Insignificantly negative \\
\hline
\end{tabular}

Table 4 represents summary of hypotheses testing for all variables. H2, H3 and H4 depict significant correlation between task dimension of performance and personality traits of conscientiousness, extraversion, and agreeableness. While $\mathrm{H} 1$ and $\mathrm{H} 5$ shows non-significant association with respect to openness to experience and neuroticism at all conventional levels of significance.

\section{CONCLUSIONS, RECOMMENDATIONS AND FUTURE STUDY}

The investigation was performed to examine and evaluate the degree and significance of relationship between big five personality attributes and employee job performance. Personality was assessed through big five personality traits, namely openness to experience, conscientiousness, extraversion, agreeableness and neuroticism; while task performance dimension was considered for the purpose of evaluating employee job performance and was measured by the time spent on completing a particular project. Multiple regression model advocates that all of the personality traits, with the exception of openness to experience and neuroticism, are found out to be effective predictors of employee job performance. The discrepancies are understandable as openness to experience is more prevalent for innovative startups and jobs requiring creativity, but emergence of startups is sporadic owing to difficult times that Pakistan is currently facing. And non-significance of neuroticism variable underlines the resilience of entrepreneurs; this attribute of Pakistan's entrepreneurs was also highlighted by Ikram et al. (2016), they suggested that they are resilient by force rather than by choice. By analyzing diversified industrial sectors and occupations, we contribute to the enhanced understanding of the personality-performance relationships. Further, the study reveals that personality predicts performance effectiveness outcomes beyond industrial sectors. 
The scenario of Pakistan serves as an appropriate platform as it is going through tough times and the widespread frustration calls for provision of desirable personality traits. The study has both theoretical and pragmatic implications, and contributes towards the debate of discovering entrepreneurial and leadership personality traits. On an applied level, our results depict that personality inventories serve as a valuable tool to stimulate entrepreneurial success. Recruitment and retention of leaders, possessing favorable personality traits as endorsed by our study, can lead to competitive advantage in the highly competitive markets of emerging economies. One of the limitation of the current study is that it does not take into consideration the cultural aspect, thus moderating effect of culture can be studied for future research avenues. Relevant study of public sector shall broaden the dimension of leaders' personality traits, since public and private sectors have different ethos and work environment. There is a need to come up with suggestions for global leadership development. Miller (2014) extended big five personality traits for the purpose of differentiating positive and negative personality traits, his work can be made more generalizable by considering the context of emerging economies like Pakistan.

\section{ACKNOWLEDGEMENT}

The research contribution has also been supported by 'Natural Science Foundation of China [Project Number: 71390333]' and 'National Science and Technology Support Program [2015BAk16B02].

\section{AUTHOR BIOGRAPHIES}

Bilal Anwar is PhD scholar at School of Management, Xi'an Jiaotong University, China. His interests lie in public private partnership, leadership strategies and regional development. He has vast industrial experience of more than 10 years in the leadership position at various multinational banks of Pakistan. Bilalbzu@yahoo.com

Dr. Zhongdong Xiao is doctoral tutor at School of Management, Xi' an Jiaotong University. His interests are in the area of industrial engineering and project management.Xzd@mail.xjtu.edu.cn

Dr. Muhammad Fiaz is Post-doctorate fellow at School of Management, Xi'an Jiaotong University. He is an Associate Professor at Institute of Business and Management, University of Engineering and Technology, Lahore, Pakistan. He has authored more than 50 peer-reviewed journal articles and presented conference papers across many countries. His research areas are related to R\&D collaboration, additive manufacturing, entrepreneurship and quality management.Fiaz0128@gmail.com

Amir Ikram is PhD student at School of Management, Xi' an Jiaotong University, China. Besides publishing articles in international journals and conference proceedings, he has contributed to numerous projects of 'National Natural Science Foundation of China'. His academic resources can be accessed from <www.amirikram12.blogspot.com>. His research interests lie in entrepreneurship, cluster strategy, supply chain management, additive manufacturing and regional development. Amirikram12@hotmail.com (Corresponding author)

Muhammad Naeem Younas is research scholar at IB\&M, University of Engineering \& Technology, Lahore, Pakistan.

\section{REFERENCES}

Alkahtani, A. H., Abu-Jarad, I., Sulaiman, M., \& Nikbin, D. (2011). The impact of personality and leadership styles on leading change capability of Malaysian managers, Australian Journal of Business and Management Research, 1(2), 70-98.

Andersen, J.A., (2000). Leadership and leadership research. In: Dahiya, D.F. (Ed.), Current Issues in Business Disciplines, vol. 5. Spellbound Publications, New Delhi, pp. 2267-2287.

Awadh, A.M. \& Wan Ismail, W. (2012). The impact of personality traits and employee work-related attitudes on employee performance with the moderating effect of organizational culture: the case of Saudi Arabia, Asian Journal of Business and Management Sciences, 1(10), 108-127.

Barrick, M. R., \& Mount, M. K. (1991). The big five personality dimensions and job performance: a meta-analysis. Personnel psychology, 44(1), 1-26. 
Barrick, M. R., Stewart, G. L., \& Piotrowski, M. (2002). Personality and Job Performance: Test of the mediating effects of motivation among sales representatives, Journal of Applied Psychology, 87, 43-51.

Bhatti, M. A., Battour, M. M., Ismail, A. R., \& Sundram, V. P. (2014). Effects of personality traits (big five) on expatriates adjustment and job performance. Equality, Diversity and Inclusion: An International Journal, 33(1), 73-96.

Blickle, G., Meurs, J. A., Wihler, A., Ewen, C., Merkl, R., \& Missfeld, T. (2015). Extraversion and job performance: How context relevance and bandwidth specificity create a non-linear, positive, and asymptotic relationship. Journal of vocational behavior, $87,80-88$.

Borman, W. C., \& Motowidlo, S. J. (1997), Task performance and contextual performance: The meaning for personnel selection research, Human performance, 10(2), 99-109.

Byrne, K. A., Silasi-Mansat, C. D., \& Worthy, D. A. (2015). Who chokes under pressure? The Big Five personality traits and decision-making under pressure. Personality and Individual Differences, 74, 22-28.

DeVellis, R.F. (2012). Scale development: Theory and applications. Los Angeles: Sage. pp. 109-110.

Chamorro-Premuzic, T., \& Furnham, A. (2010). The psychology of personnel selection. New York: Cambridge University Press.

Cohen, J., Cohen, P., West, S. G., \& Aiken, L. S. (2013). Applied multiple regression/correlation analysis for the behavioral sciences. Routledge.

Colquitt, J, Le-Pine, J, \& Wesson, M. (2009). Organizational behavior; improving performance and commitment in the workplace, New York, McGraw-Hill, Irwin.

Costa, J T, \& McCrae, R. (1992) Revised NEO Personality Inventory (NEO-PI-R) and NEO Five-Factor Inventory (NEO-FFI) professional manual. Odessa, FL: PAR.

DiNisi, A.S. (2015). Some further thoughts on entrepreneurial personality. Entrepreneurship Theory and Practice, 39, $997-1003$. Gujranwala Business Centre, 2016, Available at: http://gbc.org.pk/index.php?option=com_content\&view $=$ article \&id=49\&Itemid $=18$

Gerhart, B., \& Fang, M. (2014). Pay for (individual) performance: Issues, claims, evidence and the role of sorting effects. Human Resource Management Review, Vol. 24, No. 1, pp 41-52.

Gujarati, D.N. (1995), Basic Econometrics, 3rd ed., McGraw-Hill, New York, NY.

Haynes, K.T., Hitt, M.A., \& Campbell, J.T. (2015), The dark side of leadership: Toward a midrange theory of hubris and greed in entrepreneurial contexts. Journal of Management Studies, 52, 479-505.

Hogan, R., \& Benson, M. J. (2009), Personality, leadership, and globalization: Linking personality to global organizational effectiveness, Advances in global leadership, 5, 11-34.

Hogan, J., \& Holland, B. (2003), Using theory to evaluate personality and job-performance relations: a socio-analytic perspective, Journal of Applied Psychology, 88(1), 100.

Hurtz, G. M., \& Donovan, J. J. (2000), Personality and job performance: The Big Five revisited, Journal of Applied Psychology, 85(6), 869-879.

Ikram, A., Su, Q., \& Sadiq, M.A., (2016), Technical efficiency and its Determinants: an empirical study of surgical instruments cluster of Pakistan, Journal of Applied Business Research, 32(2), 647-660.

Jalalkamali, M., Ali, A. J., Hyun, S. S., \& Nikbin, D. (2016). Relationships between work values, communication satisfaction, and employee job performance: The case of international joint ventures in Iran. Management Decision, 54(4), 796-814.

Jeronimus B.F., Kotov, R., Riese, H., \& Ormel, J. (2016). Neuroticism's prospective association with mental disorders halves after adjustment for baseline symptoms and psychiatric history, but the adjusted association hardly decays with time: a meta-analysis on 59 longitudinal/prospective studies with 443313 participants, Psychological Medicine, 8(15), 1-24.

Jex, S. M. (1998). Stress and job performance: Theory, research, and implications for managerial practice. Sage Publications Ltd.

Judge, T. A., \& Zapata, C. P. (2015). The person-situation debate revisited: Effect of situation strength and trait activation on the validity of the Big Five personality traits in predicting job performance. Academy of Management Journal, 58(4), 11491179 .

Judge, T.A., Bono J.E. (2000). Five-factor model of personality and transformational leadership. Journal of Applied Psychology, $85(5), 751-65$.

Klotz, A. C., \& Neubaum, D. O. (2016). Research on the Dark Side of Personality Traits in Entrepreneurship: Observations from an Organizational Behavior Perspective. Entrepreneurship Theory and Practice, 40(1), 7-17.

Leutner, F., Ahmetoglu, G., Akhtar, R., \& Chamorro-Premuzic, T. (2014). The relationship between the entrepreneurial personality and the Big Five personality traits. Personality and individual differences, 63, 58-63.

Lounsbury, J. W., Smith, R. M., Levy, J. J., Leong, F. T., \& Gibson, L. W. (2009). Personality characteristics of business majors as defined by the big five and narrow personality traits. Journal of Education for Business, 84(4), 200-205.

Mark, N.B., \& John, W.L. (2000). Openness and job performance in U.S.-based Japanese manufacturing companies. Journal of Business and Psychology, 14(3), 515-522.

Miller, D. (2014). A downside to the entrepreneurial personality. Entrepreneurship Theory and Practice, 39, 1-8.

Niehoff, B.P. (2006). Personality predictors of participation as a mentor, Career Development International, 11, 321 - 333.

Norman, W. T. (1963), Toward an adequate taxonomy of personality attributes: Replicated factor structure in peer nomination personality ratings, Journal of Abnormal and Social Psychology, 66(6), 574-583.

Copyright by author(s); $\underline{\mathrm{CC}-\mathrm{BY}}$ 
Palaiou, K., Zarola, A., \& Furnham, A. (2016). The dark side of personality predicts positive and negative work attitudes. Personality and Individual Differences, 88, 12-16.

Rothmann, S., \& Coetzer, E. P. (2003). The big five personality dimensions and job performance. SA Journal of Industrial Psychology, 29(1).

Rotundo, M., \& Sackett, P. R. (2002). The relative importance of task, citizenship, and counterproductive performance to global ratings of job performance: a policy-capturing approach. Journal of Applied Psychology, 87(1), 66.

Solaja, O. M., Idowu, F. E., \& James, A. E. (2016). Exploring the relationship between leadership communication style, personality trait and organizational productivity. Serbian Journal of Management, 11(1), 99-117.

Touré-Tillery, M., \& Fishbach, A. (2014). How to measure motivation: A guide for the experimental social psychologist. Social and Personality Psychology Compass, 8(7), 328-341.

Tupes, E. C., \& Christal, R. E. (1961). Recurrent personality factors based on trait ratings. USAF ASD Tech. Rep. No. 61-97, Lackland Airforce Base, TX: U. S. Air Force

Van Veldhoven, M. A. R. C. (2014). Quantitative job demands. An introduction to contemporary work psychology, pp. 117-143.

Yeh, S. C. J., Yuan, K. S., Chen, S. H. S., Lo, Y. Y., Chou, H. C., Huang, S., ... \& Wan, T. T. (2016). The moderating effect of leadership on the relationship between personality and performance. Journal of nursing management. 